\title{
Experimental testing of density- and season-dependent growth in vegetative Fucus aquaculture and modelling of growth over one year for different cultivation scenarios
}

\author{
Rafael Meichssner ${ }^{1,2} \cdot$ Peter Krost $^{2} \cdot$ Rüdiger Schulz $^{1}$
}

Received: 21 February 2021 / Revised and accepted: 20 August 2021 / Published online: 28 September 2021

(c) The Author(s) 2021

\begin{abstract}
In the Kiel Fjord, western Baltic Sea, an experimental culture of Fucus vesiculosus and Fucus serratus has been established in order to develop a sustainable method for biomass production of these species. The cultivation method includes the unattached rearing of fronds in drifting baskets and their vegetative reproduction by cutting of small vegetative apices. In this study, we performed culture experiments to measure growth rates with this method at different initial stocking densities $\left(1-5 \mathrm{~kg} \mathrm{~m}^{-2}\right)$ and during different seasons of the year. Using the results, we modelled growth over 1 year for different cultivation scenarios (different initial stocking densities $\left(1-4.75 \mathrm{~kg} \mathrm{~m}^{-2}\right)$ and harvest densities $\left(1.25-5 \mathrm{~kg} \mathrm{~m}^{-2}\right)$ ) in order to identify optimal scenarios and estimate annual yields and the number of necessary harvests in these scenarios. Fucus vesiculosus showed a parabolic yield-density relationship with decreasing yields at high initial stocking densities $\left(>2.5 \mathrm{~kg} \mathrm{~m}^{-2}\right)$. In contrast, $F$. serratus showed an asymptotic yield-density relationship with rather constant yields at high initial stocking densities. Both species showed a typical seasonal growth pattern with low growth rates during winter and high growth rates during summer; however, $F$. serratus seemed to be growth limited during summer which was not observed for $F$. vesiculosus. The modelling results reflected the results of the Density experiment: for $F$. vesiculosus, optimal cultivation scenarios were found for intermediate cultivation densities (initial stocking densities, $1.75-2.25 \mathrm{~kg} \mathrm{~m}^{-2}$; harvest densities, 3-4 $\mathrm{kg} \mathrm{m}^{-2}$ ); for F. serratus, optimal cultivation scenarios included higher densities (initial stocking densities, $2.5-4 \mathrm{~kg} \mathrm{~m}^{-2}$; harvest density, $5 \mathrm{~kg} \mathrm{~m}^{-2}$ ). The model scenarios predicted maximal annual yields of $6.65-6.76 \mathrm{~kg} \mathrm{~m}^{-2}$ for $F$. vesiculosus and $6.88-6.99 \mathrm{~kg} \mathrm{~m}^{-2}$ for $F$. serratus. For both species, the number of harvests necessary to achieve these yields varied depending on the cultivation scenario from 2 to 6 . Scenarios with only 1 harvest per year yielded slightly lower annual yields. We conclude that the modelling results offer a valid and helpful orientation for future efforts to produce Fucus species in commercial culture.
\end{abstract}

Keywords Fucus vesiculosus $\cdot$ Fucus serratus $\cdot$ Phaeophyta $\cdot$ Aquaculture $\cdot$ Annual yield $\cdot$ Model $\cdot$ Density $\cdot$ Seasonal growth

\section{Introduction}

Today's worldwide seaweed production is dominated by farmed biomass with $97.1 \%$ of the total marketed biomass (32.4 million $\mathrm{t}$ ) origination from aquaculture (FAO 2020). Yet, a variety of species is still only produced by harvesting

Rafael Meichssner

rafael.meichssner@crm-online.de; rmeichssner@bot.uni-kiel.de

1 Physiology and Biotechnology of the Plant Cell, ChristianAlbrechts-University, Kiel, Germany

2 CRM - Coastal Research \& Management, Kiel, Germany of wild stocks (Mac Monagail et al. 2017, Lotze et al. 2019, netalgae.org). These species are often used for low-volume products like specialized cosmetics, food supplements, biostimulants etc. (Zehmke-White \& Ohno 1999, Lotze et al. 2019, netalgae.de). The two brown algal species Fucus vesiculosus and Fucus serratus are typical examples for this practice. Collection takes place in the intertidal zone of the coasts of France, Ireland, and other countries at the North Atlantic coast, and the biomass is sold frozen or dried to processing companies (Zehmke-White \& Ohno 1999, netalgae.org). As typical products, cosmetic extracts and food supplements are fabricated from Fucus due to its high content in bioactive ingredients like phlorotannins and fucoxanthin (Catarino et al. 2018, Ferreira et al. 2019, 
Torres et al. 2020). However, harvesting of wild Fucus stocks is not possible everywhere; in the Baltic Sea, Fucus stocks have experienced a dramatic decline in the second half of the twentieth century, which has been attributed mainly to eutrophication and stone fishery (Kautsky et al. 1986, Vogt and Schramm 1991, Rohde et al. 2008). As a consequence, the stocks of the German Baltic Sea coast are protected by nature protection legislation, and their harvesting for commercial purposes is prohibited (Bundesamt für Naturschutz 2013). However, a regional production in the Baltic Sea would be advantageous for German companies, as "regionality" is a desired claim in the targeted markets (L. Piker, pers. comm.). Under these circumstances, aquaculture is the only legal means for biomass production in the Baltic Sea. Aquaculture of Fucus species might also be preferable in other regions where wild populations are increasingly threatened by environmental change, like the Atlantic coasts of southern Europe (Jueterbock et al. 2013; Nicastro et al. 2013).

Hitherto, no commercial Fucus farm exists worldwide and only little related literature is published (Haglund \& Pedersen 1988; Ryzhik et al. 2014; Meichssner et al. 2020, 2021). Therefore, an experimental Fucus aquaculture was established in 2015 in the Kiel Fjord, western Baltic Sea, aiming at the development of a sustainable and regional production method for $F$. vesiculosus and $F$. serratus. The following approach has been chosen for the experimental cultivation: fronds cut above the stipe are reared unattached in baskets or net cages installed in the fjord. After a growth period, the fronds are harvested, and parts of the harvested fronds (vegetative apices) are used as seedlings for the next growing season, i.e., vegetative reproduction. Thus, the intended method is similar to Kappaphycus/Eucheuma basket culture in Indonesia (Hurtado et al. 2014). Meichssner et al. (2021) could show that the method only works if the culture biomass retains low fertility, because fertile apices (receptacles) degrade after gamete shedding, which causes severe biomass losses. The necessary low-fertility biomass can be achieved by using unattached Fucus populations with naturally low fertility as initial source of seedlings (Meichssner et al. 2021). Furthermore, a successful method for the reduction of fouling on the culture biomass has been developed (Meichssner et al. 2020).

However, the following two growth parameters in culture are yet unclear: (i) it is unclear how initial stocking density influences growth and (ii) it is unclear which growth rates are achieved during different seasons. Seasonal growth data from wild populations are available (Brenchley et al. 1998, Lehvo et al. 2001), but do not necessarily reflect growth in culture.

With respect to the density dependence of growth, it would besides be helpful to know which combination(s) of initial stocking density and harvest density (i.e., the density at which, when reached, the harvest is performed) generate the highest yield in an annual culture and how many harvests are needed in such a scenario.

\section{Materials and methods}

In order to address these questions, growth rates at different initial stocking densities and during different seasons were examined in small-scale culture experiments ("Density experiment", "Seasonal growth experiment"). Using the results of these experiments, growth in culture was modelled over 1 year for different cultivation scenarios (different initial stocking densities and harvest densities). The aim of the modelling was to answer the following questions: (1) which initial stocking densities and which harvest densities have to be chosen to reach maximum annual yields? (2) What are the maximum annual yields? (3) How many harvests have to be performed in the different cultivation scenarios?

\section{Location of the experimental farm}

The cultivation experiments were conducted at premises of Kieler Meeresfarm $\mathrm{GmbH} \& \mathrm{Co}$. KG at the northwestern shore of the Kiel Fjord in the western Baltic Sea. During the Density experiment in 2017, the experimental farm was located at $54.3758 \mathrm{~N}, 10.1620$ $\mathrm{E}$; later it had to be moved about $700 \mathrm{~m}$ along the shore to $54.3820 \mathrm{~N}, 10.1620 \mathrm{E}$, where the Seasonal growth experiment took place (see below). The moving of the farm was performed during a time when no experiments were conducted.

\section{Algal material}

Fucus plants usually grow on hard substratum to which they are attached by a discoid holdfast. From the holdfast, a rigid stipe erects which carries the flattened fronds consisting of vegetative apices and, during the reproductive season, receptacles. In the western Baltic Sea, F. vesiculosus usually reaches sizes between $20 \mathrm{~cm}$ and $1 \mathrm{~m}$ and $F$. serratus between $50 \mathrm{~cm}$ and $1 \mathrm{~m}$ (own observation).

All experiments were conducted for both Fucus species in parallel. Fucus vesiculosus was collected from Kiel Holtenau (54.3690 N; $10.1541 \mathrm{E})$ and F. serratus from Bülk $(54.4552 \mathrm{~N} ; 10.1989 \mathrm{E})$. A sufficient number of individuals $(>5)$ was collected to achieve genotypically mixed experimental biomasses. The collected individuals were transported as whole plants in sea water to the experimental site where they were stored in buckets overnight. The next day, vegetative fronds of 3-10 cm (F. vesiculosus) and 5-15 cm (F. serratus) were cut from the plants and used for the start 
of the experimental cultures. The size range is typical for fronds found in the field when cut above the stipe. In order to ensure an even distribution of frond sizes and genotypes among the experimental units, a bulk of fronds was prepared from which random portions of the desired weight were taken to inoculate the experimental units. In a parallel experiment (results published in Meichssner et al. 2020), this method for the assembly of biomass yielded $4.5 \pm 1.3$ fronds per $10 \mathrm{~g}$ of experimental biomass with $43 \pm 7$ meristems for $F$. vesiculosus ( $N=14$ examined experimental units) and $3.4 \pm 0.7$ fronds per $10 \mathrm{~g}$ of experimental biomass with $15 \pm 2$ meristems for $F$. serratus ( $N=9$ examined experimental units). The maximum observed relative deviation of the normalized meristem number (meristems per $10 \mathrm{~g}$ biomass) from the mean was $27 \%$ for $F$. vesiculosus and $12 \%$ for $F$. serratus. Deviations of single replicates from the mean number of meristems seemed to have no significant impact on the growth behavior: no correlation was observed between the relative deviation of the normalized meristem number from the mean of the treatment group and the relative deviation of the relative daily growth rates, measured over the following 14 days, from the mean of the treatment group (see Supplementary material, Fig. S1). Thus, this method of assembling the experimental biomass is in our opinion close to aquacultural practice and allows for valid measurements of growth at the same time. The size difference between $F$. vesiculosus and $F$. serratus was accepted as no direct comparison between the species was intended.

Meichssner et al. (2021) have shown that low-fertility biomass from unattached Fucus populations is needed for successful long-term cultivation, because fertility-related biomass losses (degradation of receptacles after gamete shedding) are otherwise too strong. Unfortunately, the experiments for the present study were initiated before the results of Meichssner et al. (2021) were obtained.
Therefore, the experiments presented here were still conducted with biomass originating from attached populations. However, as only fronds with vegetative apices were used and the experimental time was very short, i.e., only beginning receptacle initiation and no receptacle degradation did occur during the experiments, we consider the growth in these experiments as vegetative and thus comparable to the growth of biomass from unattached lowfertility populations.

\section{Cultivation baskets}

Black plastic baskets (BAUHAUS; Oase Pflanzkorb; edge length, $28 \mathrm{~cm}$; volume, $14 \mathrm{~L}$ ) were used for cultivation, which allowed for water inflow by holes of ca. $3 \times 3 \mathrm{~mm}$ size (Fig. 1a). The baskets were covered with transparent plastic nettings to avoid the loss of culture material. Eight baskets were connected to packages of $3 \times 3$ baskets with the central position left empty. The packages were inserted into white boxes (glass fiber-reinforced plastic; shape, turned truncated pyramid; upper opening, $80 \times 80 \mathrm{~cm}$; basal area, $64 \times 64 \mathrm{~cm}$; height, ca. $40 \mathrm{~cm}$ ) (Fig. 1b), which were deployed in the fjord using the gaps of a Jetfloat system (Jetfloat International) (double elements, $100 \times 50 \times 40 \mathrm{~cm}$; single elements, $50 \times 50 \times 40 \mathrm{~cm}$ ) (Fig. 1c). The white boxes had four side windows $(35 \times 37 \mathrm{~cm})$ allowing for water inflow. Using this construction, the baskets were lowered to a depth of ca. $10 \mathrm{~cm}$ into the fjord, resulting in an $20 \times 20 \mathrm{~cm}$ submerged cultivation area per basket. Six white boxes were available, yielding 48 baskets as experimental units. Experimental groups were distributed randomly in the white boxes; in addition, the position of the baskets within the white boxes was changed regularly to avoid position effects.
Fig. 1 Experimental cultivation baskets used in the Seasonal growth experiment and the Density experiment. Eight baskets were connected to one package (a) inserted in a white box (b), which allowed for water inflow by four side windows. Six boxes equipped with cultivation baskets were installed in the fjord by help of a Jetfloat system (c)

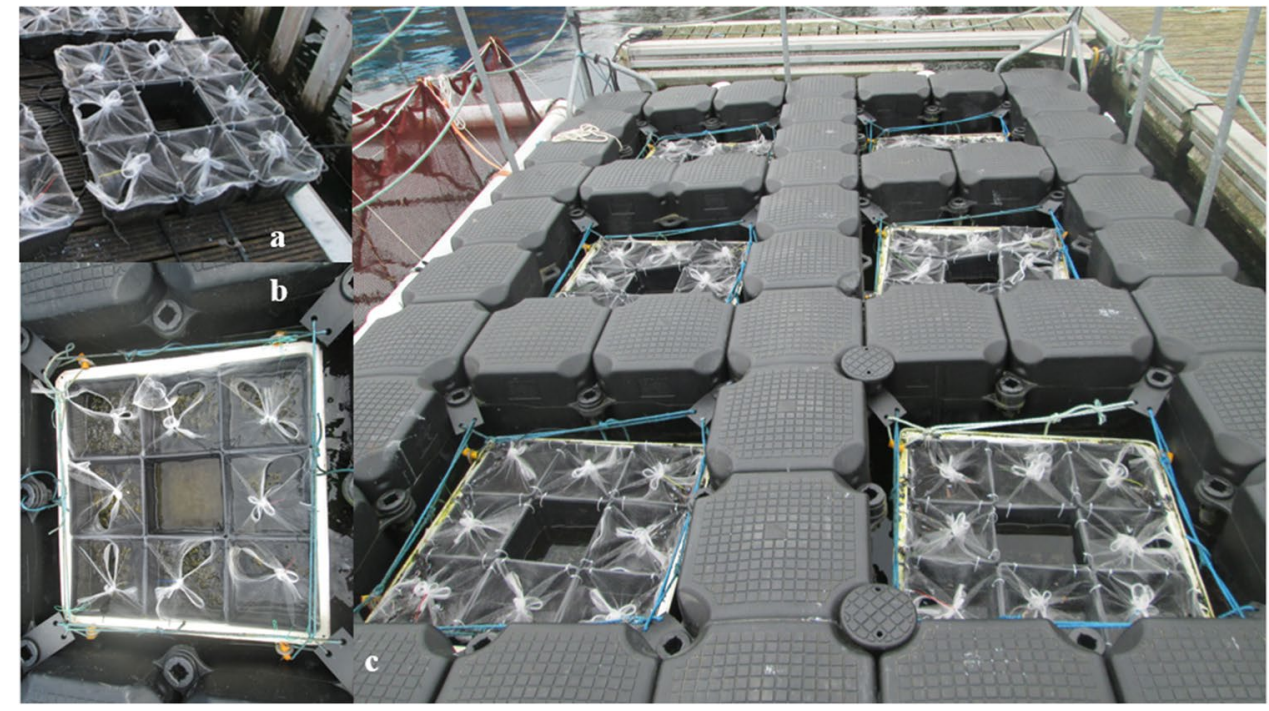




\section{Weight measurements}

In all experiments, growth was measured as change in wet weight. All weights given in the following represent wet weights. For comparative purposes, the following dry matter contents can be assumed: $F$. vesiculosus, $21 \pm 2 \%$ and F. serratus, $24 \pm 1 \%$ (own pre-experiments). Wet weight measurements were performed with a lab scale (Kern EMB 1200) under wind protected conditions at the experimental site. Before weighing, the fronds were spun with a salad spinner for $15 \mathrm{~s}$ in portions of maximum $150 \mathrm{~g}$ to remove attached water.

\section{Environmental data}

Environmental data are provided for the Seasonal growth experiment. Water temperature within the cultivation baskets was logged every 60 min with a Hobo pendant data logger. Daily totals of photosynthetically active photon flux density (PPFD) were recorded in the Botanical Garden of Kiel University, $4.87 \mathrm{~km}$ from the experimental site as described in Pescheck and Bilger (2019) and Meichssner et al. (2020). The mesh used to cover the baskets reduced the incoming irradiance by $4 \pm 2 \%$. This mesh-related irradiance reduction increased to $12 \pm 4 \%$ after 3-4 weeks when the mesh was colonized by microalgae. Nutrient data (concentrations of $\mathrm{NO}_{2}^{-}, \mathrm{NO}_{3}{ }^{-}, \mathrm{NH}_{4}{ }^{+}, \mathrm{PO}_{4}{ }^{3-}$ in $1 \mathrm{~m}$ depth) from the Mönkeberg measurement station (ca. $3 \mathrm{~km}$ from the cultivation site within the Kiel Fjord: 54.3538 N; 10.1647 E) were kindly provided by LLUR (Landesamt für Landwirtschaft, Umwelt und ländliche Räume Schleswig-Holstein). Additional nutrient data (concentrations of $\mathrm{NO}_{2}{ }^{-}, \mathrm{NO}_{3}{ }^{-}, \mathrm{NH}_{4}{ }^{+}, \mathrm{PO}_{4}{ }^{3-}$ in $1 \mathrm{~m}$ depth) with a slightly higher temporal resolution were available from the Boknis Eck time series station (ca. $30 \mathrm{~km}$ from the cultivation site in the Kiel bay, $54.5167 \mathrm{~N} ; 10.0333$ E) (Lennartz et al. 2014). They were kindly provided by Kastriot Qelaj and Hermann Bange. Even though the actual concentrations at the experimental site might vary slightly from the concentrations measured at Mönkeberg and Boknis Eck, the data provide a good indication of the ambient nutrient dynamics, nutrient availabilities, and potentially limiting nutrient species. The environmental data are shown in the Supplementary material (Figs. S2 and S3, Tabs. S1 and S2).

\section{Density experiment}

Eight different initial stocking densities (40, 80, 100, 120, $140,160,180,200 \mathrm{~g} \mathrm{basket}^{-1}, N=3$ ) were compared corresponding to $1,2,2.5,3,3.5,4,4.5$, and $5 \mathrm{~kg} \mathrm{~m}^{-2}$. The experiment lasted from 24 May 2017 to 04 July 2017.

For all groups, relative daily growth rates $(R D G)$ were calculated over the entire experimental time ( 41 days) by the following formula:
$R D G=\ln \left(D_{t} / D_{0}\right) *(100 / t)$

where $R D G$ is the relative daily growth rate in percent day $^{-1}, D_{t}$ is the density at a given date in $\mathrm{kg} \mathrm{m}^{-2}, D_{0}$ is the initial stocking density in $\mathrm{kg} \mathrm{m}^{-2}$, and $t$ is the number of days between $D_{0}$ and $D_{t}$.

In addition, the yield $(Y)$ in $\mathrm{kg} \mathrm{m}^{-2}$ was calculated:

$Y=D_{t}-D_{0}$

Fitting of the data from the Density experiment was performed with the program Qtiplot using the Levenberg-Marquardt method (Kelley 1999). There are at least three reasonable options for the fitting of $R D G-D_{0}$ relationships: first, a fit equation derived from the traditional yield-density equation for land plants (Li et al. 2016) (see Supplementary material), which assumes that the maximum $R D G$ at $x=0$ is approached in a steep manner and the minimum $R D G$ at high densities in a rather asymptotic manner; second, a linear fit equation; third, a sigmoidal fit equation assuming that the highest $R D G s$ at low densities as well as the lowest $R D G s$ at high densities are approached in an asymptotic manner. All three options yielded similar $R^{2}$ values ( $F$. vesiculosus, $0.92-0.93 ; F$. serratus; linear fit equation, 0.81 ; fit equation derived from traditional yield density equation and sigmoidal fit equation, 0.85). A sigmoidal fit equation seemed in our opinion most appropriate, due to the following reasons: (i) RDGs at very low densities are expected to be rather equal as competition for light, nutrients etc. becomes irrelevant at very low densities (own observation). (ii) $R D G s$ from 3.5 to $5 \mathrm{~kg} \mathrm{~m}^{-2}$ were not significantly different for both Fucus species (Tukey's HSD for all possible group comparisons between 3.5 and $5 \mathrm{~kg} \mathrm{~m}^{-2}: p>0.05$ ). This corresponds to a sigmoidal approximation towards a theoretical infinite density. (iii) The $R D G$ cannot be $0 \% \mathrm{day}^{-1}$ or lower at a theoretical infinite density and should asymptotically approach a minimum at high densities. Therefore, we decided to use a sigmoidal Boltzmann fit equation for the $R D G-D_{0}$ relationship:

$R D G=A_{2}+\left(A_{1}-A_{2}\right) /\left(1+\exp \left(\left(D_{0}-x_{0}\right) / d x\right)\right)$

where $A_{1}$ represents the initial value, i.e., the fitted maximum $R D G$ at the minimum density, and $A_{2}$ represents the final value, i.e., the fitted minimum $R D G$ at the maximum density. $x_{0}$ is the turning point, i.e., the density at which the change in $R D G$ is highest; $d x$ is the time constant; it can be used to calculate the slope at $x_{0}$ by the following formula: slope $=\left(A_{1}-A_{2}\right) / 4 d x$. Especially the parameters $A_{1}$ and $A_{2}$ adopted unrealistic values because the available data points did not include very low and very high densities, respectively, and thus did not allow for a precise fitting of a wide density range. This was accepted since the fit was only used 

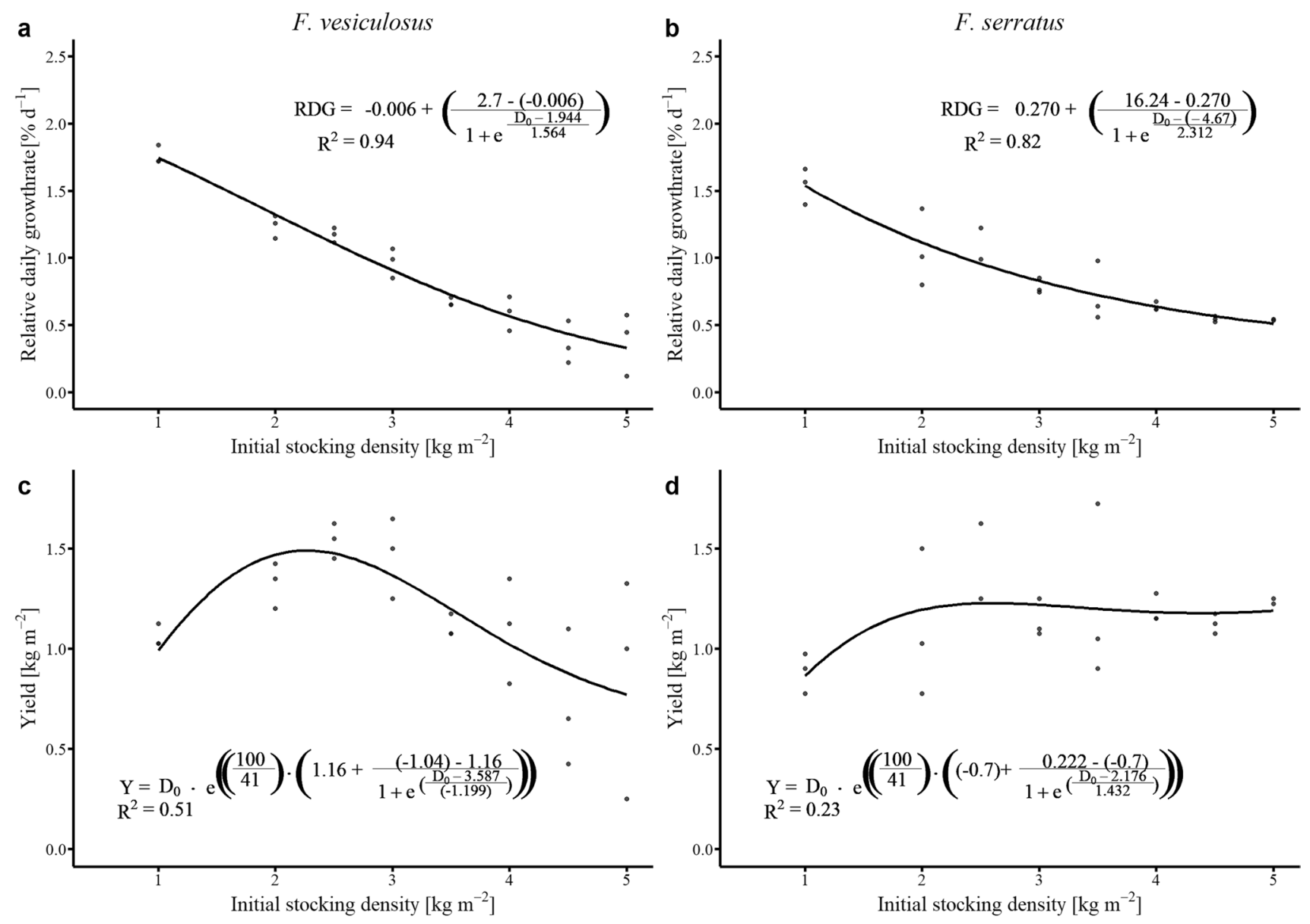

Fig. 2 a, b Relative daily growth rate in $\%$ day $^{-1}$ of $F$. vesiculosus and $F$. serratus at 8 different initial stocking densities from 1 to $5 \mathrm{~kg} \mathrm{~m}^{-2}$ $(N=3)$ after an experimental cultivation of 41 days (24 May to 04 Jul 2017). The data were fitted with a sigmoidal Boltzmann equations. Resulting equations with parameters and $R^{2}$ values are given

in the graphs. c, d Yield of $F$. vesiculosus and F. serratus in $\mathrm{kg} \mathrm{m}^{-2}$ obtained in the same experiment after 41 days of cultivation. The fit equation for the yield was obtained from the sigmoidal Boltzmann fit equation for the $R D G$ (see "Material and methods")

to represent the experimentally tested culture-relevant densities which were later included in the modelling (see below). The RDGs at these densities were well represented by the fit (Fig. 2).

For fitting the yield-density relationship, we used an equation deduced from the fit equation for the $R D G$ (Eq. 3). For this purpose, Eq. 3 was inserted into the following Eq. 4, which describes the calculation of the yield from the $R D G$ :

$Y=D_{0} * \exp ((100 / t) * R D G)$

In case of the Density experiment, $t=41$ days. The resulting fit equation for the yield-density relationship was

$Y=D_{0} * \exp \left((100 / 41) *\left(A_{2}+\left(A_{1}-A_{2}\right) /\left(1+\exp \left(\left(D_{0}-x_{0}\right) / d x\right)\right)\right)\right)$

In this case, the parameters $\left(A_{1}, A_{2}, x_{0}, d x\right)$ do not relate to any specific growth features of the cultivated seaweed anymore.

The fit equations for the $R D G-D_{0}$ relationship and yield $-D_{0}$ relationship based on a traditional equation for land plants (see above) are shown in the Supplementary material.

\section{Seasonal growth experiment}

Growth was measured over 1 year (15 December 2018 to 15 December 2019) in eight periods of ca. 1.5 months each. The cultures of each period $(N=3)$ were started with $20 \mathrm{~g}$ fronds basket ${ }^{-1}$ (i.e., $0.5 \mathrm{~kg} \mathrm{~m}^{-2}$ ). The relative daily growth rates over the 1.5 months were calculated by Eq. 1 .

\section{Modelling of annual yield}

Annual yield was modelled in Microsoft Excel for the period 15 December 2018 to 15 December 2019 (parallel to the 
Seasonal growth experiment). To create model scenarios, initial stocking densities $\left(1-4.75 \mathrm{~kg} \mathrm{~m}^{-2}\right.$, intervals of $0.25 \mathrm{~kg} \mathrm{~m}^{-2}$ ) and harvest densities $\left(1.25-5 \mathrm{~kg} \mathrm{~m}^{-2}\right.$, intervals of $0.25 \mathrm{~kg} \mathrm{~m}^{-2}$ ) were defined. For every possible combination of initial stocking density and harvest density, the annual yield as well as the required number of harvests was modelled. For this purpose, the density for each single day of the year was modelled using the following formula:

$m D_{t}=D_{t-1} *\left(1+\left(z * m R D G_{t-1}\right)\right)$

where $m D_{t}$ is the modelled density at a given day, $D_{t-1}$ is the density of the day before, and $m R D G_{t-1}$ is the relative daily growth rate for $D_{t-1}$, which was calculated by inserting $D_{t-1}$ as " $D_{0}$ " into Eq. 3. $z$ is a seasonal correction factor, which corrects $m R D G_{t-1}$ for the growth rate of the specific period of the year. It was calculated as the ratio of the $R D G$ measured during each specific period of the year in the Seasonal growth experiment and the $R D G$ measured during period 4, which is the time when the Density experiment was conducted in 2017.

If $m D_{t}$ reached the defined harvest density, the density of the next day was set to the defined initial stocking density, which was considered as harvest. The annual yield was then calculated by the following formula:

Annual yield $=$ No. of harvests $*\left(d D_{h}-d D_{0}\right)+\left(m D_{365}-d D_{0}\right)$

where $d D_{h}$ is the defined harvest density, $d D_{0}$ is the defined initial stocking density, and $m D_{365}$ is the modelled density of day 365 of the modelled year.

\section{Statistical analysis}

Statistical analysis was performed with R (R Core Team 2013). For the Density experiment and the Seasonal growth experiment, the RDGs of the groups were compared by oneway ANOVA and post-hoc Tukey's HSD test (in part to validate the used fitting method in the Density experiment, see above). Normality of residuals was tested by Shapiro-Wilk test and homogeneity of residuals by Fligner's test.

\section{Results}

\section{Density experiment}

The average measured $R D G s$ decreased with increasing initial stocking density for both species, for $F$. vesiculosus from $1.76 \pm 0.07 \% \mathrm{day}^{-1}$ at $1 \mathrm{~kg} \mathrm{~m}^{-2}$ initial stocking density to $0.38 \pm 0.23 \% \mathrm{day}^{-1}$ at $5 \mathrm{~kg} \mathrm{~m}^{-2}$ initial stocking density, and for $F$. serratus from $1.54 \pm 0.13$ to $0.54 \pm 0.01 \%$ day $^{-1}$ (Fig. 2a, b). This stronger decrease for $F$. vesiculosus was reflected in a significantly steeper fit curve than for $F$. serratus. The obtained fit parameters and $R^{2}$ values of the fit curves are given in Fig. 2.

The measured yields after 41 days of cultivation ranged between 0.25 and $1.65 \mathrm{~kg} \mathrm{~m}^{-2}$ for $F$. vesiculosus and between 0.78 and $1.73 \mathrm{~kg} \mathrm{~m}^{-2}$ for $F$. serratus (Fig. 2c, d). Average yields increased linearly at low initial stocking densities for both species. For $F$. vesiculosus, the maximum average yield $\left(1.54 \pm 0.08 \mathrm{~kg} \mathrm{~m}^{-2}\right)$ was found at an initial stocking density of $2.5 \mathrm{~kg} \mathrm{~m}^{-2}$, for $F$. serratus, the maximum average yield $\left(1.43 \pm 0.27 \mathrm{~kg} \mathrm{~m}^{-2}\right)$ was also found at an initial stocking density of $2.5 \mathrm{~kg} \mathrm{~m}^{-2}$. At initial stocking densities above $2.5 \mathrm{~kg} \mathrm{~m}^{-2}$, the yields decreased for $F$. vesiculosus and remained rather stable for $F$. serratus, resulting in a parabolic fit curve for the first species and a rather asymptotic curve for the latter (see "Discussion"). The fit parameters and $R^{2}$ values are given in Fig. 2.

\section{Seasonal growth experiment}

Fucus vesiculosus showed a typical seasonal growth curve with the highest $R D G s$ in summer $\left(2.43 \pm 0.35 \%\right.$ day $^{-1}$ in July) and the lowest RDGs in winter $\left(0.33 \pm 0.09 \% \mathrm{day}^{-1}\right.$ in January, one-way ANOVA over all groups, $p<0.0001$, $d f=7$ ) (Fig. 3). Fucus serratus also showed seasonal differences (one-way ANOVA over all groups: $p<0.0001$, $d f=7$ ) but without a pronounced peak in summer. In contrast, average growth rates were rather constant from April to October (Tukey's HSD: $p>0.05$ for all possible group comparisons between April and October) and ranged between 1.38 and $1.46 \%$ day $^{-1}$. The lowest growth rates of $F$. serratus were observed in January $\left(0.34 \pm 0.03 \% \mathrm{day}^{-1}\right)$.

\section{Environmental data during Seasonal growth experiment}

During the Seasonal growth experiment, the water temperature varied between a short-time minimum of $0{ }^{\circ} \mathrm{C}$ in February 2019 and a short-time maximum of $26^{\circ} \mathrm{C}$ in July 2019 (Supplementary material, Fig. S2). The daily total of the photosynthetically active photon flux density (PPFD) varied between $0.7 \mathrm{~mol} \mathrm{~m}^{-2} \mathrm{day}^{-1}$ at 16 November 2019 and $60.1 \mathrm{~mol} \mathrm{~m}^{-2} \mathrm{day}^{-1}$ at 22 June 2019 (Supplementary material, Fig. S3). Nutrient concentrations of the sea region showed the typical annual cycle with maximal concentrations in winter and lower concentrations in summer (Supplementary material, Tabs. S1, S2). N:P ratios of the measured inorganic nutrient species varied between 0.7 and 15.2 (with one outlier of 82 ) which indicates that in 

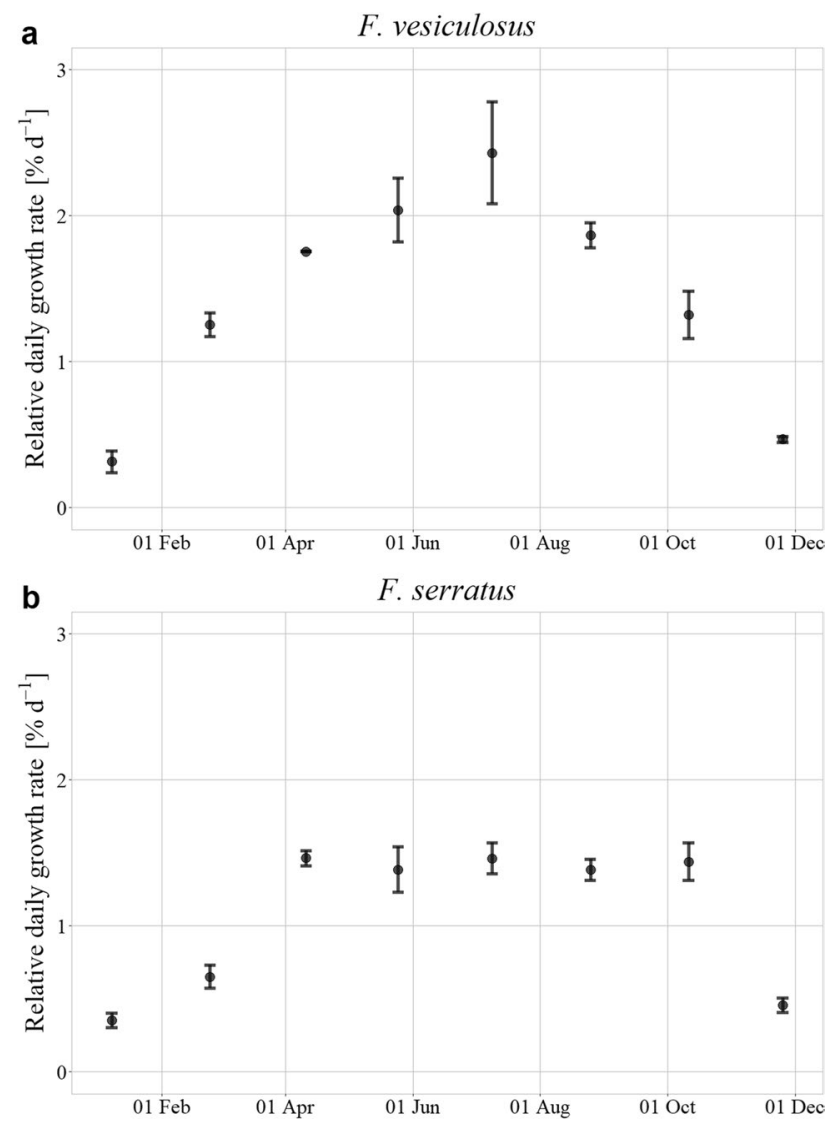

Fig. 3 Relative daily growth rate in $\%$ day $^{-1}$ of $F$. vesiculosus (a) and $F$. serratus $(\mathbf{b})$ in culture over the course of 1 year (15 December 2018 to 15 December 2019), measured in eight intervals of ca. 1.5 months. The $R D G$ was measured for an initial stocking density of $0.5 \mathrm{~kg} \mathrm{~m}^{-2}$; it is displayed as mean $\pm \mathrm{SD}(N=3)$ at the middle day of each cultivation period

case of nutrient limitation, nitrogen would be the limiting element (N:P ratio of uptake, 30-40 (Gordillo et al. 2002); tissue N:P ratio, ca. 30 (Harrison and Hurd 2001; Pedersen et al. 2010)). This corresponds to the general observation that nitrogen is the limiting nutrient for seaweed growth in temperate sea regions (Hurd et al. 2014; Roleda and Hurd 2019).

\section{Modelling of growth over 1 year}

For $F$. vesiculosus, the modelled annual yields ranged between 4.06 and $6.76 \mathrm{~kg} \mathrm{~m}^{-2}$. The highest annual yields were obtained when initial stocking densities ranged between 1.75 and $2.25 \mathrm{~kg} \mathrm{~m}^{-2}$ and harvest densities between 3 and $4 \mathrm{~kg} \mathrm{~m}^{-2}$. This reflects the shape of the yield-density curve (see above). The annual yields of the optimal scenarios ranged between 6.65 and $6.76 \mathrm{~kg} \mathrm{~m}^{-2}$ (requiring 2-6 harvests) (Fig. 4, Table 1). The best scenario requiring
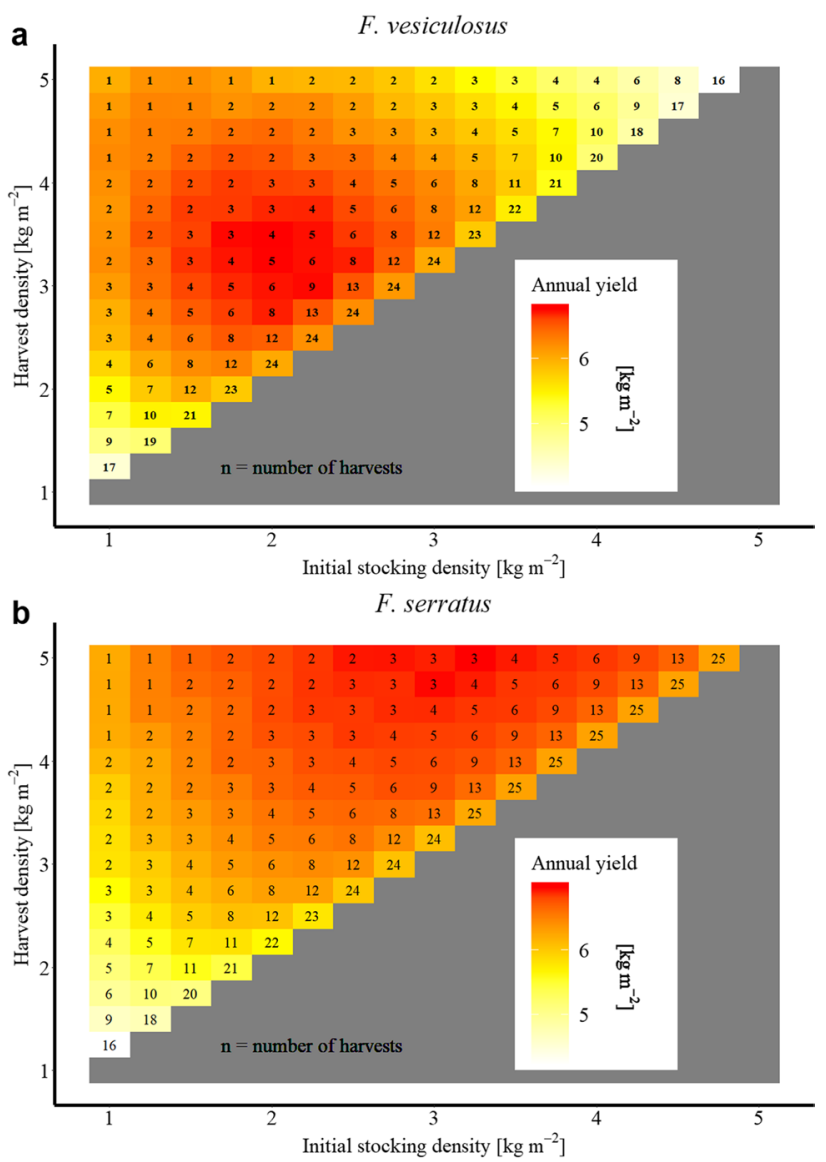

Fig. 4 Modelled annual yield (indicated by color) and necessary number of harvests (indicated by numbers) for $F$. vesiculosus (a) and $F$. serratus (b). Yield and necessary number of harvests were modelled for all possible combinations of initial stocking density and harvest density in the range of $1-5 \mathrm{~kg} \mathrm{~m}^{-2}$ (intervals of $0.25 \mathrm{~kg} \mathrm{~m}^{-2}$ )

only 1 harvest resulted in a slightly lower annual yield $\left(6.31 \mathrm{~kg} \mathrm{~m}^{-2}\right.$ ) (Table 1).

For $F$. serratus, the annual yields obtained from the model varied between 4.23 and $6.99 \mathrm{~kg} \mathrm{~m}^{-2}$. The highest annual yields were found for initial stocking densities between 2.5 and $4 \mathrm{~kg} \mathrm{~m}^{-2}$ and a harvest density of $5 \mathrm{~kg} \mathrm{~m}^{-2}$, again reflecting the shape of the yield-density curve (see above). In the optimal scenarios, the annual yields ranged between 6.88 and $6.99 \mathrm{~kg} \mathrm{~m}^{-2}$ (requiring 2-6 harvests) (Fig. 4, Table 1). The best scenario with only 1 necessary harvest also estimated a slightly lower annual yield $\left(6.69 \mathrm{~kg} \mathrm{~m}^{-2}\right)$ (Table 1). Annual yields higher than the modelled maximum annual yield were obtained, if harvest densities of more than $5 \mathrm{~kg} \mathrm{~m}^{-2}$ were allowed in the model. However, a validation of these model scenarios by real data was not possible as densities above $5 \mathrm{~kg} \mathrm{~m}^{-2}$ were not tested in the Density experiment; therefore, these scenarios were excluded from the model. 
Table 1 Maximum annual yields for 1-6 required harvests and the corresponding initial stocking density and harvest density. The overall maximum annual yield obtained from the model is indicated in bold

\begin{tabular}{llll}
\hline No. of harvests & $\begin{array}{l}\text { Max. annual } \\
\text { yield }\left[\mathrm{kg} \mathrm{m}^{-2}\right]\end{array}$ & $\begin{array}{l}\text { Initial stocking } \\
\text { density }\left[\mathrm{kg} \mathrm{m}^{-2}\right]\end{array}$ & $\begin{array}{l}\text { Harvest density } \\
{\left[\mathrm{kg} \mathrm{m}^{-2}\right]}\end{array}$ \\
\hline F. vesiculosus & & & \\
1 & 6.314 & 1.25 & 4.5 \\
2 & 6.646 & 1.75 & 4 \\
3 & 6.757 & 1.75 & 3.5 \\
4 & $\mathbf{6 . 7 6 3}$ & 2 & 3.5 \\
5 & 6.761 & 2 & 3.25 \\
6 & 6.756 & 2.25 & 3 \\
F. serratus & & & \\
1 & 6.689 & 1.5 & 5 \\
2 & 6.965 & 2.5 & 5 \\
3 & $\mathbf{6 . 9 8 8}$ & 3.25 & 5 \\
4 & 6.958 & 3.5 & 5 \\
5 & 6.918 & 3.75 & 5 \\
6 & 6.881 & 4 & 5 \\
\hline
\end{tabular}

\section{Discussion}

In this study we determined the growth rates of Fucus vesiculosus and Fucus serratus in vegetative aquaculture for different initial stocking densities and during different seasons. Based on the results, we modelled growth in culture over 1 year under different cultivation scenarios (different initial stocking densities and harvest densities). The model results (Fig. 4) offer a useful picture of the best cultivation scenarios for the two species. Fucus vesiculosus should be grown at intermediate densities $\left(1.75-4 \mathrm{~kg} \mathrm{~m}^{-2}\right)$, while $F$. serratus should be grown at higher densities $\left(2.5-5 \mathrm{~kg} \mathrm{~m}^{-2}\right)$. The model provides an estimation of the potential annual yields and the number of harvests necessary to achieve these annual yields. The results of the single experiments as well as the applicability of the model results to commercial-scale culture will be discussed in the following.

Both Fucus species showed a clear density dependence of measured relative daily growth rates and yields in the Density experiment. The yield-density curves of the two species differed markedly; $F$. vesiculosus showed a clear peak at ca. $2.5 \mathrm{~kg} \mathrm{~m}^{-2}$ density with a significant reduction of the yield at higher densities, while $F$. serratus showed no significant reduction of the yield at high densities (Fig. 2c, d). Thus, the yield-density relationships can be regarded as parabolic for $F$. vesiculosus and asymptotic for $F$. serratus following the definition by Assefa et al. (2016), who describe asymptotic behavior as "yield increase with increasing plant density to a maximum, without decreasing afterward," and parabolic behavior as "increases in yield with density to a maximum density, with lower yields as density increases further" (see also Holliday 1960, Bleasdale \& Nelder 1960, Yahuza 2011, $\mathrm{Li}$ et al. 2016). The parabolic behavior of $F$. vesiculosus might be due to the presence of vesicles in a part of the $F$. vesiculosus fronds. Vesiculated fronds drifted at the surface which caused a shading of unvesiculated fronds lying on the ground of the basket. This effect was probably proportionally stronger at high densities, as the same percentage of vesiculated fronds that would, e.g., cover $20 \%$ of the surface of a low-density basket would cover almost the entire surface of a high-density basket. Thus, the yields of highdensity groups might have been reduced by proportionally stronger shading resulting in a parabolic yield-density curve. This process could also be an explanation for the high yield variation among replicates of $F$. vesiculosus at high densities, as replicates with many vesiculated fronds might have experienced a stronger reduction of growth than replicates with few vesiculated fronds. Unfortunately, the percentage of vesiculated fronds was not quantified and did in addition change during the experiment as the fronds produced new vesicles. $F$. serratus produces no vesicles; thus, no shading by drifting fronds occurred resulting in an asymptotic yield-density curve. We assume that the shape of the $F$. vesiculosus yield-density curve would shift towards asymptotic behavior, if fronds from unattached populations, which usually produce no vesicles (Norton and Mathieson 1983), were used for cultivation (Meichssner et al. 2021).

In the Seasonal growth experiment, a marked seasonality of the growth rates was found with low growth rates in winter and high growth rates in summer (Fig. 3), which reflects the seasonal growth cycle of Fucus species in the wild (e.g., Brenchley et al. 1998; Lehvo et al. 2001). Growth rates remained at levels $>0.3 \%$ day $^{-1}$ during winter. Interestingly, $F$. serratus growth seemed to be limited during summer with rather constant growth rates between April and October, while F. vesiculosus showed a clear peak in July. How to explain this difference? Growth in general is the result of intrinsic growth regulation as well as all abiotic (e.g., temperature, light availability, nutrient concentrations) and biotic (e.g., grazing, fouling) factors acting jointly on the cultivated fronds. Intrinsic regulation leading to a growth limitation in summer has never been observed in Fucus species and can be excluded as cause for the limited growth of $F$. serratus during summer. As no severe grazing or fouling was observed in the experiments, biotic effects are also unlikely to be causal for the observed difference. Temperature might be an explanatory factor as the growth rate decrease at temperatures above the optimum of $15{ }^{\circ} \mathrm{C}$ is slightly stronger for $F$. serratus than for F. vesiculosus, at least for North Sea individuals (Fortes and Lüning 1980). Unfortunately, there are no studies comparing the temperature-growth relationship of Baltic Sea populations of both species (but see Graiff et al. 2015 for F. vesiculosus). Light stress is unlikely to be the reason for the observed pattern as the growth limitation of $F$. serratus did not occur 
specifically during the time of highest irradiances (June to July, Supplementary material, Fig. S3) and higher growth rates have been observed in other experiments in which the fronds experienced stronger light exposure (Meichssner et al. 2020, see below). The timing of the growth limitation of $F$. serratus coincided with the time of lowest ambient nutrient concentrations (Supplementary material, Tabs. S1, S2), suggesting that growth of $F$. serratus might have been nutrient-limited. Fucus species are able to store nutrients during times of excess nutrient concentrations (typically occurring in winter) and utilize them during summer when ambient nutrient concentrations are low. Limitation commences as soon as internal reserves are used up, usually in late summer (Perdersen and Borum 1996, Lehvo et al. 2001). It is, however, unclear if/how the conditions in the cultivation baskets have altered the exploitability of available nutrients. The reduced water motion within the baskets might have led to an increased thickness of the diffusive boundary layer and thus a less efficient nutrient uptake (Lichtenberg et al. 2017). It is further unclear if the used Baltic Sea populations of the two Fucus species differ in their nutrient storage capacities and in their requirements of nitrogen, which was the limiting element according the ambient nutrient concentrations (DIN:DIP $<15$ (Supplementary material, Tabs. S1, S2), tissue N:P of both species ca. 30 (Harrison and Hurd 2001; Pedersen et al. 2010; Gordillo et al. 2002)). The mentioned reduced water motion within the experimental baskets might have had additional negative effects, like reduction of DIC uptake or reduction of removal of metabolic waste products, which might have caused the limited growth of $F$. serratus during summer. In conclusion, the cause(s) for the observed growth limitation of $F$. serratus during summer remain unclear. It might also have been different causes during different times of the limitation period, e.g., temperature stress during July/August (Fortes and Lüning 1980) and nutrient limitation during September (Pedersen and Borum 1996) or combinations of causes.

From the data of the Density experiment and the Seasonal growth experiment, annual growth was modelled (Fig. 4). The model results seem reasonable: (i) the yields reflect the measured growth rates integrated over 1 year. (ii) Many harvests were calculated if the difference between initial stocking density and harvest density was small and few harvests were calculated if it was large. (iii) The model calculated highest annual yields at intermediate densities for $F$. vesiculosus and at higher densities for $F$. serratus, which reflects the shape of the experimentally determined yield-density curves of the two species (Fig. 2). Thus, we conclude that the used model is a suitable tool for the forecasting of growth over 1 year in the used experimental system. However, there are two assumptions underlying the model that need to be mentioned: first, the model assumes that the density-growth dependence measured in the Density experiment applies at all seasons. Second, the model assumes that continuous growth can be simulated based on growth rates which were measured from material which was freshly collected each time (in the Seasonal growth experiment). These assumptions were not tested experimentally as this would have been very laborious and would probably not have improved the model significantly. Even though it might be that the density-growth relationship is slightly altered during winter when significantly less photons are available, it is unlikely that the general pattern of the model results will be significantly affected especially since growth in winter is generally low and contributes only little to the overall growth. The second assumption can in part be validated by the observation that vegetative Fucus fronds retain their growth potential in continuous culture (Meichssner et al. 2021). Besides, fresh collection involves the cutting of fronds (including the need for wound healing) as does the production of seedlings from the harvest in a continuous culture. Therefore, the uncertainties introduced by this assumption were accepted.

The main objective of the modelling was to identify optimal cultivation scenarios, i.e., combinations of initial stocking density and harvest density, which can be used in future cultivation efforts. The modelled yields (maximal $6.65-6.76 \mathrm{~kg} \mathrm{~m}^{-2}$ for $F$. vesiculosus and $6.88-6.99 \mathrm{~kg} \mathrm{~m}^{-2}$ for $F$. serratus), however, have to be considered with caution as growth rates can be different, for example, in improved cultivation devices: both underlying experiments (Density experiment, Seasonal growth experiment) were conducted in baskets deployed in the gaps of a Jetfloat system (Fig. 1), where water exchange was limited and light levels were slightly reduced by the surrounding Jetfloat elements. In a parallel cultivation experiment (May to June 2019), where identical experimental baskets were deployed directly in the fjord (Meichssner et al. 2020), the measured daily growth rates were $59 \%$ higher for $F$. vesiculosus and $51 \%$ higher for $F$. serratus than at the same time in the Seasonal growth experiment. If the modelling was corrected by these higher growth rates, maximum annual yields of $10.62 \mathrm{~kg} \mathrm{~m}^{-2}$ for $F$. vesiculosus and $10.48 \mathrm{~kg} \mathrm{~m}^{-2}$ for $F$. serratus were obtained (the corrected modelling results for improved growth conditions are shown in the Supplementary material, Fig. S4). Thus, we believe that the model correctly estimated the annual yields under the given experimental conditions, but the non-optimal experimental cultures have led to an underestimation of the actual potential of vegetative Fucus aquaculture. However, as the combination of initial stocking density and harvest density as well as the required number of harvests was only slightly affected if the model was run with higher growth rates, the principal pattern of the model results can be used as an orientation for the planning of Fucus cultivation efforts, even though higher yields could be expected with other, more optimized cultivation conditions.

For long-term commercial culture, fronds from unattached populations are necessary as they seem to retain 
their naturally low fertility in culture, thus having the potential to be cultivated continually without the biomass losses related to receptacle degradation (Meichssner et al. 2021). In the present study, we still used vegetative fronds from attached origin as the experiments were initiated before the results of Meichssner et al. (2021) were obtained. We believe that the modelling results of this study in principle do also apply for the culture of unattached populations. However, it has to be considered that the optimal combination of initial stocking density and harvest density for unattached and therefore unvesiculated F. vesiculosus fronds (Norton and Mathieson 1983) might shift to higher densities (similar to the $F$. serratus model results), as the yield-density relationship underlying the model is assumed to shift towards asymptotic behavior (see above).

Another aspect of commercial culture was also not covered by the model: it has to be considered that the production of seedlings for the next cultivation season must be automated, for example by shredding. Seedling biomass which is generated by shredding of harvested biomass is of course less optimally cut than the fronds used in this study and will probably show lower growth rates. The development of a suitable automated seedling production process as well as the influence of this process on the growth potential of the seedling biomass require further studies.

In general, it is unclear if the modelled yields can be transferred to hectare scales as scaling effects like potential nutrient limitation or grazer accumulation can hardly be predicted. In a first upscaling attempt, similar growth rates were observed for $1.2 \mathrm{~m}^{2}$ cages as for the small cultivation baskets used in the experiments presented here (own observation); however, the used cages were not optimized yet. If a direct scalability is assumed, annual harvests of $33.5 \mathrm{t} \mathrm{ha}^{-1}$ and $34.5 \mathrm{t} \mathrm{ha}^{-1}$ could be expected for $F$. vesiculosus and $F$. serratus, respectively (based on the modelled yields, assuming 5,000 $1 \mathrm{~m}^{2}$ baskets $\mathrm{ha}^{-1}$ and $50 \%$ of the space left for boating). Even higher yields might be possible if cultivation conditions are optimized (see above). The calculated yields per hectare are lower than the typical yields of farmed Laminariales (except for Alaria esculenta) (Kraan 2010), which was expected considering the comparatively high growth rates of Laminariales. Yet, it has to be remembered that Fucus is not produced for its high growth potential but for its high-priced end products. Thus, a cultivation at the modelled yields could still be profitable even at smaller scales. Land-based cultivation, similar to Gracilaria tank culture (Friedlander \& Levy 1995), might also be profitable if it is combined with biomass processing and valorization (Piker L., pers. comm.). We assume that the cultivation parameters determined in this study (optimal initial stocking densities and harvest densities) do also apply to culture in flat landbased tanks.
Open-water Fucus cultures might serve as nutrient sink for eutrophic water bodies (Rönneberg et al. 1992, Fei 2004, see also Ryzhik et al. 2014): based on the tissue nitrogen and phosphorous content (ca. $2 \%$ and $0.2 \%$ of the dry weight (Rönneberg et al. 1992; Pedersen et al. 2010; Perini and Bracken 2014)), 1 ton of harvested $F$. vesiculosus biomass would remove ca. $4.2 \mathrm{~kg}$ nitrogen and ca. $420 \mathrm{~g}$ phosphorous from the water column (assuming a dry matter content of $21 \%$ (own pre-experiments)), and 1 ton of harvested $F$. serratus biomass would remove ca. $4.8 \mathrm{~kg}$ nitrogen and $480 \mathrm{~g}$ phosphorous (assuming a dry matter content of $24 \%$ (own pre-experiments)). However, it is unclear if the produced biomass would still be useful for high-value products as high epiphyte loads can be expected in nutrient-rich cultures (Rönneberg et al. 1992; Worm and Sommer 2000). The same is true if Fucus cultures are intended as nutrient trap for fish aquaculture (Rönneberg et al. 1992). Even though Fucus growth can be nutrientlimited during short periods of the year even in nutrientrich sea areas (Pedersen and Borum 1996), fertilization of commercial cultures should be avoided considering the overall eutrophic state of many temperate coastal waters and especially the Baltic Sea.

As mentioned before, biomass from unattached Fucus populations is needed for commercial Fucus cultures (Meichssner et al. 2021). Only small amounts should be collected in order to protect these valuable habitats, and collection should be accompanied by regular monitoring of the used populations (Meichssner et al. 2021). In an optimal scenario, only little biomass from the field is initially collected and used to build a larger culture over time (Meichssner et al. 2021). Local populations should be used, as the introduction of culture material from foreign populations bears the risk of introducing (i) non-native Fucus genotypes and (ii) non-native Fucusassociated species like crustaceans, snails, and epiphytic algae.

An alternative to the introduced vegetative cultivation approach would be a cultivation technique including sexual reproduction, i.e., the production of zygotes by mixing of female eggs and male spermatozoids, and their subsequent seeding on cultivation ropes, which are transplanted to the sea for outgrowth to harvest size. This technique would be similar to the cultivation techniques used for the production of Saccharina spp., Undaria pinnatifida, and PorphyralPyropia spp. (Graham et al. 2009; Hurd et al. 2014). Protocols for the production of Fucus zygotes are well established (e.g., Bogaert et al. 2015), and an implementation in an aquaculture process should be possible. However, it has to be noted that Fucus eggs and zygotes are not mobile like the spores of Laminariales. Therefore, the fertilized zygotes have to have the opportunity to sink on and attach to the 
used ropes/cultivation structures, which contrasts to the cultivation technique used for Laminariales, where the culture ropes can be submerged in spore solution and the spores actively swim towards the rope (Hurd et al. 2014). A potential low-effort method for the seeding of ropes would be the installation of ropes in natural Fucus beds during the reproductive season and the transfer to the cultivation site after zygotes have attached.

\section{Summary and outlook}

Fucus vesiculosus and $F$. serratus show species-specific growth rate patterns with respect to initial stocking density and cultivation season in experimental vegetative aquaculture. The determined growth rates were used to model annual growth in experimental vegetative Fucus aquaculture. The model results (optimal initial stocking densities and harvest densities, potential yields, and necessary numbers of harvests) provide a helpful orientation for the planning of future efforts to establish commercial Fucus aquaculture. Future research should focus on large-scale implementation including the development of suitable cultivation devices for either open-water net cage culture or land-based tank culture. Other challenges including the efficient dealing with grazing and fouling as well as the establishment of low-fertility culture populations require further investigations. Apart from vegetative culture, cultivation of Fucus by sexual reproduction (i.e., the seeding of zygotes on ropes) could be a promising alternative approach.

Supplementary Information The online version contains supplementary material available at https://doi.org/10.1007/s10811-021-02597-8 .

Acknowledgements We thank Studienstiftung des Deutschen Volkes, Fazit-Stiftung, and the Interreg 5a-project Fucosan for funding the research. We also thank Kieler Meeresfarm GmbH \& Co. KG for providing their farm facilities for the experiments and taking care of the experimental baskets during storm events. Furthermore, we thank Dagobert Sachs for help with the Density experiment, Florian Weinberger for helpful discussions about the study concept and results, and Armin Gnutzmann for help with the construction of a first upscaling approach. We owe special thanks to Frauke Pescheck for providing the irradiance data and to Kastriot Qelaj, Hermann Bange, and the LLUR (Landesamt für Landwirtschaft, Umwelt und ländliche Räume Schleswig-Holstein) for providing the nutrient data from the Boknis Eck time series station and the Mönkeberg measurement station.

Author contribution Rafael Meichssner conducted the experimental work, data analysis, and modelling and wrote the first draft of the manuscript. Peter Krost assisted in the analysis and interpretation of the data. Rüdiger Schulz assisted in the planning of the study. Peter Krost and Rüdiger Schulz reviewed and edited the manuscript.

Funding Open Access funding enabled and organized by Projekt DEAL. The study was funded by Studienstiftung des Deutschen Volkes, Fazit- Stiftung, and the Interreg5a-project FucoSan.
Data availability The datasets generated during and/or analyzed during the current study are available from the corresponding author on reasonable request.

\section{Declarations}

Conflict of interest The authors declare no competing interests.

Open Access This article is licensed under a Creative Commons Attribution 4.0 International License, which permits use, sharing, adaptation, distribution and reproduction in any medium or format, as long as you give appropriate credit to the original author(s) and the source, provide a link to the Creative Commons licence, and indicate if changes were made. The images or other third party material in this article are included in the article's Creative Commons licence, unless indicated otherwise in a credit line to the material. If material is not included in the article's Creative Commons licence and your intended use is not permitted by statutory regulation or exceeds the permitted use, you will need to obtain permission directly from the copyright holder. To view a copy of this licence, visit http://creativecommons.org/licenses/by/4.0/.

\section{References}

Assefa Y, Vara Prasad PV, Carter P, Hinds M, Bhalla G, Schon R, Jeschke M, Paszkiewicz S, Ciampitti IA (2016) Yield responses to planting density for US modern corn hybrids: a synthesisanalysis. Crop Sci 56:2802-2817

Balina K, Romagnoli F, Blumberga D (2016) Chemical composition and potential use of Fucus vesiculosus from Gulf of Riga. Energy Procedia 95:43-49

Bleasdale JKA, Nelder JA (1960) Plant population and crop yield. Nature 188:342

Bogaert KA, Beeckman T, De Clerck O (2015) Photoplarization of Fucus zygotes is determined by time sensitive vectorial addition of environmental cues during axis amplification. Front Plant Sci 6:26

Bordeyne F, Migne A, Plus M, Davoult D (2020) Modelling the annual primary production of an intertidal brown algal community based on in situ measurements. Mar Ecol Prog Ser 656:95-107

Brenchley JL, Raven JA, Johnston AM (1998) Carbon and nitrogen allocation patterns in two intertidal fucoids: Fucus serratus and Himanthalia elongata. Eur J Phycol 33:307-313

Bundesamt für Naturschutz (2013) Rote Liste gefährdeter Tiere, Pflanzen und Pilze Deutschlands, Band 2: Meeresorganismen. BfN-Schriftenvertrieb, Bonn, Bad Godesberg, pp 179-218

Catarino MD, Silva AM, Cardoso SM (2018) Phycochemical constituents and biological activities of Fucus spp. Mar Drugs 16:249

Demetropoulos CL, Langdon CJ (2004) Enhanced production of Pacific dulse (Palmaria mollis) for co-culture with abalone in a land-based system: effects of stocking density, light, salinity, and temperature. Aquaculture 235:471-488

FAO (2020) The State of World Fisheries and Aquaculture 2020. Sustainability in action. FAO, Rome

Fei X (2004) Solving the coastal eutrophication problem by large scale seaweed cultivation. Hydrobiologia 512:145-151

Ferreira RM, Ribeiro AR, Patinha C, Silva AMS, Cardoso SM, Costa R (2019) Water extraction kinetics of bioactive compounds of Fucus vesiculosus. Molecules 24:3408.

Fortes MD, Lüning K (1980) Growth rates of North Sea macroalgae in relation to temperature, irradiance and photoperiod. Helgoländer Meeresunters 34:15-29

Friedlander M, Levy I (1995) Cultivation of Gracilaria in outdoor tanks and ponds. J Appl Phycol 7:315-325 
Gordillo FJL, Dring MJ, Savidge G (2002) Nitrate and phosphate uptake characteristics of three species of brown algae cultured at low salinity. Mar Ecol Prog Ser 234:111-118

Graham LE, Graham JM, Wilcox LW (2009) Algae, 2nd edn. Pearson Education, San Francisco

Graiff A, Liesner D, Karsten U, Bartsch I (2015) Temperature tolerance of western Baltic Sea Fucus vesiculosus - growth, photosynthesis and survival. J Exp Mar Biol Ecol 471:8-16

Haglund K, Pedersen M (1988) Spray cultivation of seaweeds in recirculating brackish water. Aquaculture 72:181-189

Harrison PJ, Hurd CL (2001) Nutrient physiology of seaweeds: application of concepts to aquaculture. Cah Biol Mar 42:71-82

Holliday R (1960) Plant population and crop yield. Nature 186:22-24

Hurd LH, Harrison PJ, Bischof K, Lobban CS (2014) Seaweed ecology and physiology, 2nd edn. Cambridge University Press, Cambridge

Hurtado AQ, Gerung GS, Yasir S, Critchley AT (2014) Cultivation of tropical red seaweeds in the BIMP-EAGA region. J Appl Phycol 26:707-718

Jueterbock H, Tyberghein L, Verbruggen H, Coyer JA, Olsen JL, Hoarau G (2013) Climate change impact on seaweed meadow distribution in North Atlantic rocky intertidal. Ecol Evol 3:1356-1373

Kautsky N, Kautsky H, Kautsky U, Waern M (1986) Decreased depth penetration of Fucus vesiculosus (L.) since the 1940s indicates eutrophication of the Baltic Sea. Mar Ecol Prog Ser 28:1-8

Kelley CT (1999) Iterative methods for optimization. SIAM Press, Philadelphia

Knight M, Parke M (1950) A biological study of Fucus vesiculosus L. and $F$. serratus L. J Mar Biol Assoc 29:439-501

Kraan S (2010) Mass-cultivation of carbohydrate rich macroalgae, a possible solution for sustainable biofuel production. Mitig Adapt Strateg Glob Chang 18:1-20

Lamela-Silvarrey C, Fernández C, Anadón R, Arrontes J (2012) Fucoid assemblages at the North coast of Spain: past and present (19772007). Bot Mar 55:199-207

Lehvo A, Bäck S, Kiirikki M (2001) Growth of Fucus vesiculosus L. (Phaeophyta) in the Northern Baltic Proper: energy and nitrogen storage in seasonal environment. Bot Mar 44:345-350

Lennartz ST, Lehmann A, Herford J, Malien F, Hansen HP, Biester H, Bange HW (2014) Long-term trends at the Boknis Eck time series station (Baltic Sea), 1957-2013: does climate change counteract the decline in eutrophication? Biogeosciences 11:6323-6339

Li L, Weiner J, Wang Y, Wang S, Zhou DW (2016) Yield-density relationships of above- and belowground organs in Allium cepa var. aggregatum populations. Plant Ecol 217:913-922

Lichtenberg M, Nørregaard RD, Kühl M (2017) Diffusion or advection? Mass transfer and complex boundary layer landscapes of the brown alga Fucus vesiculosus. J R Soc Interface 14: 20161015

Lotze HK, Milewski I, Fast J, Kay L, Worm B (2019) Ecosystem-based management of seaweed harvesting. Bot Mar 62:395-409

Lüning K (1985) Meeresbotanik - Verbreitung, Ökophysiologie und Nutzung der marinen Makroalgen. Georg Thieme Verlag, Stuttgart

Mac Monagail M, Cornish L, Morrison L, Araujo R, Critchley AT (2017) Sustainable harvesting of wild seaweed resources. Eur J Phycol 52:371-390

Mata LFR (2008) Integrated aquaculture of Bonnemaisoniaceae: physiological and nutritional controls of biomass production and of halogenated metabolite content. PhD Thesis, University of Algarve, Portugal

Mata L, Santos R (2003) Cultivation of Ulva rotundata (Ulvales, Chlorophyta) in raceways, using semi-intensive fishpond effluents: yield and biofiltration. In: Chapman A, Anderson RJ, Vreeland VJ, Davison IR (eds) Proceedings of the 17th International
Seaweed Symposium, Cape Town 2001. Oxford University Press, Oxford, pp 237-242

Meichssner R, Krost P, Schulz R (2021) Vegetative aquaculture of Fucus in the Baltic Sea - obtaining low fertility biomass from attached or unattached populations? J Appl Phycol 33:1709-1720

Meichssner R, Stegmann N, Cosin AS, Sachs D, Bressan M, Marx H, Krost P, Schulz R (2020) Control of fouling in the aquaculture of $F$. vesiculosus and $F$. serratus by regular desiccation. J Appl Phycol 32:4245-4158

Netalgae.eu. Accessed 15 July 2018

Nicastro KR, Zardi GI, Teixeira S, Neiva J, Serrao EA, Pearson GA (2013) Shift happens: trailing edge contraction associated with recent warming trends threatens a distinct genetic lineage in the marine macroalga Fucus vesiculosus. BMC Biol 11:6

Norton TA, Mathieson AC (1983) The biology of unattached seaweeds. In: Round FE, Chapmann DJ (eds) Progress in Phycological Research, vol 2. Elsevier, Amsterdam, pp 333-376

Pedersen MF, Borum J (1996) Nutrient control of algal growth in estuarine waters. Nutrient limitation and the importance of nitrogen requirements and nitrogen storage among phytoplankton and species of macroalgae. Mar Ecol Prog Ser 142:261-272

Pedersen MF, Borum J, Fotel FL (2010) Phosphorous dynamics and limitation in fast- and slow-growing temperate seaweeds in Oslofjord, Norway. Mar Ecol Prog Ser 309:103-115

Perini V, Bracken MES (2014) Nitrogen availability limits phosphorus uptake in an intertidal macroalga. Oecologia 175:667-676

R Core Team (2013) R: a language and environment for statistical computing. R Foundation for Statistical Computing, Vienna. http:// www.R-project.org/. Accessed 19 Oct 2019

Pescheck F, Bilger W (2019) High impact of seasonal temperature changes on acclimation of photoprotection and radiation-induced damage in field grown Arabidopsis thaliana. Plant Physiol Biochem 134:129-136

Rohde S, Hiebenthal C, Wahl M, Karez R (2008) Decreased depth distribution of Fucus vesiculosus (Phaeophyceae) in the Western Baltic: Effects of light deficiency and epibionts on growth and photosynthesis. Eur J Phycol 43:143-150

Roleda MY, Hurd CL (2019) Seaweed nutrient physiology: application of concepts to aquaculture and bioremediation. Phycologia $58: 552-562$

Rönneberg O, Ådjers K, Ruokolahti C, Bondestam M (1992) Effects of fish farming on growth, epiphytes and nutrient content of Fucus vesiculosus L. in the Aland archipelago, northern Baltic Sea. Aquat Bot 42:109-120

Ryzhik IV, Makarov MV, Voskoboinikov GM (2014) The physiological state of intertidal brown seaweeds Fucus serratus Linnaeus, 1753 and Fucus distichus Linnaeus, 1767 cultivated on a biofiltration system in the Barents Sea. Russ J Mar Biol 40:119-124

Torres MD, Kraan S, Dominguez H (2020) Sustainable seaweed technologies, cultivation, biotechnology and applications. Elsevier, Amsterdam

Vogt H, Schramm W (1991) Conspicious decline of Fucus in Kiel Bay (Western Baltic): what are the causes? Mar Ecol Prog Ser 69:189-194

Worm B, Sommer U (2000) Rapid direct and indirect effects of a single nutrient pulse in a seaweed-epiphyte-grazer system. Mar Ecol Prog Ser 202:283-288

Yahuza I (2011) Yield-density equations and their application for agronomic research: a review. Int J Biosci 5:1-17

Zehmke-White WL, Ohno M (1999) World seaweed utilization: an end-of-century summary. J Appl Phycol 11:369-376

Publisher's note Springer Nature remains neutral with regard to jurisdictional claims in published maps and institutional affiliations. 